OPEN ACCESS

Edited by:

Sinisa Savic,

University of Leeds, United Kingdom

Reviewed by:

Darren Newton,

University of Leeds, United Kingdom

Eleni Gavriilaki,

G. Papanikolaou General Hospital,

Greece

${ }^{*}$ Correspondence:

Zonghong Shao

shaozonghong@sina.com

${ }^{\text {t}}$ These authors have contributed equally to this work

Specialty section: This article was submitted to Autoimmune and Autoinflammatory

Disorders,

a section of the journal

Frontiers in Immunology

Received: 07 October 2021 Accepted: 03 December 2021 Published: 24 December 2021

Citation:

Li C, Dong X, Wang H and Shao Z (2021) The Role of T Lymphocytes in

the Pathogenesis of Paroxysmal

Nocturnal Hemoglobinuria.

Front. Immunol. 12:777649.

doi: 10.3389/fimmu.2021.777649

\section{The Role of T Lymphocytes in the Pathogenesis of Paroxysmal Nocturnal Hemoglobinuria}

\author{
Chenyuan $\mathrm{Li}^{\dagger}$, Xifeng Dong ${ }^{\dagger}$, Huaquan Wang and Zonghong Shao* \\ Department of Hematology and Oncology, Tianjin Medical University General Hospital, Tianjin, China
}

Paroxysmal nocturnal hemoglobinuria (PNH) is an acquired hematopoietic stem cell genetic mutation disease that causes defective erythrocyte membrane hemolysis. Its pathologic basis is the mutation of the PIG-A gene, whose product is necessary for the synthesis of glycosylphosphatidylinositol (GPI) anchors; the mutation of PIG-A gene results in the reduction or deletion of the GPI anchor, which leads to the deficiency of GPI-anchored proteins (GPI-APs), such as CD55 and CD59, which are complement inhibitors. The deficiency of complement inhibitors causes chronic complement-mediated intravascular hemolysis of GPI-anchor-deficient erythrocyte. PIG-A gene mutation could also be found in bone marrow hematopoietic stem cells (HSCs) of healthy people, but they have no growth advantage; only the HSCs with PIG-A gene mutation in $\mathrm{PNH}$ patients have this advantage and expand. Besides, HSCs from PIG-A-knockout mice do not show clonal expansion in bone marrow, so PIG-A mutation cannot explain the clonal advantage of the PNH clone and some additional factors are needed; thus, in recent years, many scholars have put forward the theories of the second hit, and immune escape theory is one of them. In this paper, we focus on how T lymphocytes are involved in immune escape hypothesis in the pathogenesis of $\mathrm{PNH}$.

Keywords: paroxysmal nocturnal hemoglobinuria, aplastic anemia, T lymphocytes, pathogenesis, immune escape

\section{INTRODUCTION}

Paroxysmal nocturnal hemoglobinuria (PNH) is an acquired hematopoietic stem cell (HSC) genetic mutation disease, causing defective erythrocyte membrane hemolysis. It is a benign clonal disease, characterized by intravascular hemolysis, hemoglobinuria, venous thrombosis, and bone marrow failure (1). In 2007, the incidence of PNH was reported to be 1.59 per 100,000 people in the United Kingdom (2). According to a recent study, the incidence rate of PNH and aplastic anemia (AA)PNH syndrome was about 0.35 cases per 100,000 people per year, and the overall prevalence rate was 3.81 per 100,000 (3). If not diagnosed or treated well, it can cause a $35 \%$ death rate within 5 years (4). Due to the low incidence rate of $\mathrm{PNH}$, the disease may be ignored easily, which often leads to misdiagnoses and missed diagnoses.

The pathophysiology of $\mathrm{PNH}$ is the genetic mutation of Phosphatidylinositol glycan anchor biosynthesis, class A(PIG-A) gene on chromosome Xp22.1, whose gene product is necessary for the synthesis of glycosylphosphatidylinositol (GPI) anchors; the reduction or deletion of the GPI anchor is the result of mutation of PIG-A gene, which leads to the deficiency of GPI-anchored 
proteins (GPI-APs) (Figure 1) (5). There are a large number of GPI-APs on the cell surface, including complement regulatory proteins like complement decay-accelerating factor (DAF, CD55) and membrane inhibitor of reactive lysis (MIRL, CD59), both of which are complement inhibitors; the primary function of CD55 is to dissociate and inactivate the C3 convertases, and CD59 prevents the formation of membrane attack complex (MAC or C5b-9 complex). The deficiency of these complement inhibitors causes chronic complementmediated intravascular hemolysis of GPI-anchor-deficient erythrocyte $(2,6,7)$. Early this century, the use of the anti-C5 antibody eculizumab has changed the management of $\mathrm{PNH}$ patients and may further improve their life (8). Noval complement inhibitors, like ravulizumab, a long-term C5 inhibitor, and pegcetacoplan, a C3 inhibitor, have also been now approved with $\mathrm{PNH}$. New drugs like factor D and factor B inhibitors are in development $(9,10)$. Allogeneic hematopoietic stem cell transplantation (Allo-HSCT) is an option for $\mathrm{PNH}$ patients, which can effectively and safely eliminate the $\mathrm{PNH}$ clone with satisfactory overall survival (11).

$P I G$ - $A$ gene mutation could also be found in bone marrow hematopoietic stem cells (HSCs) of normal people, but they have no growth advantage under normal conditions; only the PIG-A gene mutation-HSCs in patients with $\mathrm{PNH}$ have this advantage, as well as clonal expansion (12), and HSCs from PIG-A-

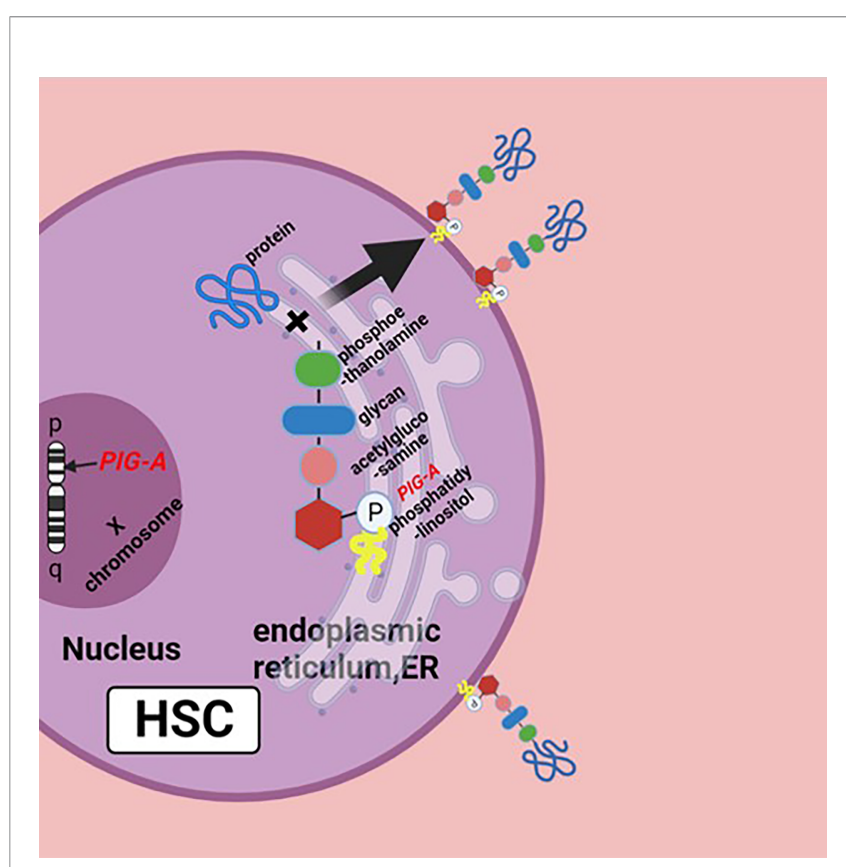

FIGURE 1 | Biosynthesis of GPI molecules: PIG-A gene is located on chromosome Xp22.1, whose product is necessary for the synthesis of GPI. In endoplasmic reticulum (ER), the assembly of phosphatidylinositol,

acetylglucosamine, and glycan consisting of three mannose molecules and a phosphoethanolamine is the first step of GPI synthesis. GPI and protein form a complex, then the GPI-protein complex transfers to the cell surface, and the GPI molecule becomes the anchor of the protein. The mutation of PIG-A gene causes the deficiency of GPIs and GPI-APs, or none at all. Figure was created in BioRender.com. knockout mice do not show clonal expansion in the bone marrow (13), so PIG-A gene mutation alone cannot explain how the PNH clone can expand. Thus, in recent years, many scholars have put forward the theories of the second hit (2), and immune escape theory is one of them, which considers that HSCs expressing GPI-APs are killed by autoimmune cytotoxic lymphocytes (CTLs); however, GPI-APs-deficient HSCs can escape (14). This idea was first proposed 2 decades ago and is supported by several studies. Therefore, this paper focuses on how $\mathrm{T}$ lymphocytes are involved in immune escape hypothesis in the pathogenesis of $\mathrm{PNH}$.

\section{T LYMPHOCYTES' IMMUNITY IS ABNORMAL IN PNH PATIENTS}

\section{Abnormal T lymphocytes' Clones Were Found in Patients With PNH}

Luzzatto L summarized their findings and then found that T-lymphocyte populations clonally expanded in many PNH patients (15). Fragments of peptides on major histocompatibility complex (MHC) molecules can activate $\mathrm{T}$ cells of the same MHC alleles. The subsequent cloning of the two chains of T-cell receptor (TCR), including $\alpha$ chain and $\beta$ chain, which can specifically recognize the peptide/MHC, was found in the human body, supporting a model in the process of $\mathrm{T}$-cell activation, in which proteins are digested and become short peptides, which combine with the MHC molecule, and then $\mathrm{T}$ cells of the same MHC alleles recognize these peptide/MHCs via the mutual effect between TCR and peptide/ MHC. TCRs have three variable regions. Complementary determining region-3 (CDR-3) of the beta variable (V $\beta$ ) chain is one of them; as the main driver of recognition between TCR and peptide/MHC, it can regulate the specificity of the TCR/ MHC interaction (16). T-cell activation requires two signals: TCR's recognition of the $\mathrm{MHC} /$ peptide and the co-signal delivered by the interaction between the co-signaling molecule and its receptor. Risitano et al. found an overexpression of $\mathrm{V} \beta$ families in $\mathrm{PNH}$ and AA patients compared to normal control by V $\beta$ cytometry (17). They used TCR flow cytometry and CDR-3 analysis to assess clonality of $\mathrm{T}$ lymphocytes and found that TCR-V $\beta$-specific expansions were detected in $10 \mathrm{PNH}$ patients and $14 \mathrm{AA} / \mathrm{PNH}$ patients, and among four of them, extreme expansions of one $\mathrm{V} \beta$-subset of $\mathrm{CD}^{+} / \mathrm{CD} 28^{-} / \mathrm{CD} 56^{+}$(effector) phenotype were found, which is very similar to large granulocytic lymphocytic (LGL) leukemia (18); these lines of evidence support the idea that $\mathrm{T}$ lymphocyte is involved in the pathogenesis of $\mathrm{PNH}$.

\section{PNH Is Closely Related to AA, Which Is an Autoimmune and Bone Marrow Destructive Disease}

Clinical features of $\mathrm{PNH}$ include severe hemolysis, thrombosis, and cytopenia; bone marrow failure is regarded as its clinical manifestation, which is very similar to AA (19), and analysis of the databases found that about half of the PNH patients had a 
previous history of AA (20). Frickhofen et al. found in several clinical studies that Ham test results of AA patients turned positive after several months of immunosuppressive therapy (IST) with anti-thymocyte globin (ATG) and cyclosporine-A (CsA); it turns out that patients with AA may evolve into $\mathrm{PNH}$ (21). Colony analysis results of $\mathrm{PNH}$ patients were similar to those of AA patients (22). Some experts think that PNH is a unique subset of the AA. Increasing lines of evidence show that $\mathrm{T}$ lymphocytes cause HSC damage in AA patients and that the IST can overcome AA; therefore, autoimmune-mediated HSC destruction plays an important role in the pathogenesis of AA (23). Autoimmune response requires the participation of $\mathrm{CD} 4^{+}$, $\mathrm{CD}^{+} \mathrm{T}$ cells, natural killer (NK) cells, and so on (24), and it is widely recognized that dysregulated $\mathrm{CD} 4^{+} \mathrm{T}$ cells, $\mathrm{CD} 8^{+} \mathrm{T}$ cells, and NK cells, and the production of various cytokines, such as interferon-gamma (IFN- $\gamma$ ), tumor necrosis factor-alpha (TNF$\alpha$ ), and transforming growth factor-beta (TGF- $\beta$ ), induce autoimmune-mediated apoptosis of HSCs in AA patients (25). All of these support the immune escape model of $\mathrm{PNH}$, indicating that the autoimmunity in which $\mathrm{T}$ lymphocytes are involved in may play an important role in the pathogenesis of the disease.

\section{Immunosuppressive Therapy Is Effective in Some Patients With PNH}

Kulagin et al. evaluated the influence that PNH clones may exert on 125 AA patients treated with IST; they were divided into two groups: the patients with the $\mathrm{PNH}$ clone group ( $\mathrm{PNH}+$ group) and the patients with no $\mathrm{PNH}$ clone group (PNH- group). After 6 months of IST, the response rate was higher in the $\mathrm{PNH}+$ group than that in the PNH-group (26). Ren et al. found that the $\mathrm{PNH}$ clone predicts a faster response to IST in severe AA patients (27). ATG is an immunosuppressant that mainly acts on activated $\mathrm{T}$ lymphocytes, which can reduce the number of $\mathrm{T}$ lymphocytes. Seven PNH patients were treated with ATG in Paquette's research, and three of them experienced improvement (28). Nakasone et al. applied ATG in the treatment of 4 patients with PNH; ATG was administered at a dose of $15 \mathrm{mg} / \mathrm{kg}$ and continued for 5 days. During the treatment, the patients showed aggravation of hemolysis and thrombocytopenia, and they all received blood transfusion of components such as RBCs and platelets, but no renal failure or thrombosis occurred during the therapy, and the anemia symptoms of the patients were all improved within 1 year (29). IST is effective in some PNH patients, further suggesting that the autoimmunity that $\mathrm{T}$ lymphocytes are involved in may play a role in the pathogenesis of the disease. However, Schubert et al. found that PNH clones appeared in some AA patients after IST (30); does that mean IST can drive PNH? Li et al. found in their study of 678 AA patients that, after IST, only 43 cases' $\mathrm{PNH}$ clone switched from negative to positive and the $\mathrm{PNH}$ clone disappeared in 47 cases (31). Zhang et al. found that after IST, the PNH clone switched from negative to positive in $24 \mathrm{AA}$ patients, remained positive $\mathrm{PNH}$ in $22 \mathrm{AA}$ patients, and disappeared in 10 AA patients; these changes had no significant influence on overall responsive rates and survival rates (32). So far, IST is indeed effective for some $\mathrm{PNH}$ patients, but whether IST can drive PNH is still controversial.

\section{DIFFERENCES BETWEEN GPI- AND GPI+ CELLS IN PATIENTS WITH PNH}

\section{The Proliferation Ability of GPI' Cells and $\mathrm{GPI}^{+}$Cells in Patients With PNH Is Different}

Han Bing et al. found that, compared to $\mathrm{PNH} \mathrm{CD} 34^{+} \mathrm{CD} 59^{+}$ cells, $\mathrm{PNH} \mathrm{CD} 4^{+} \mathrm{CD} 59^{-}$cells had a higher ability of plating efficiency, colony formation, and cell expansion (33). CD160 is a kind of GPI-AP, which is mainly expressed on the surface of some cells with cytotoxic activity, such as $\mathrm{CD}^{+} \mathrm{T}$, natural killer T (NKT) cells, and NK cells (34). As for the function of the CD160 molecule, it is recently believed that CD160 plays a co-inhibitory role by strongly binding to herpes virus entry mediator (HVEM) (35). CD160 inhibits proliferation of human T cells upon ligation to HVEM (36). Liu et al. separated $\mathrm{CD} 160^{+}\left(\mathrm{GPI}^{+}\right) \mathrm{CD}^{+} \mathrm{T}$ cells and $\mathrm{CD} 160^{-}\left(\mathrm{GPI}^{-}\right) \mathrm{CD}^{+} \mathrm{T}$ cells into two different groups, stimulated the cells in the two groups by IL-2, respectively, and observed the proliferation of cells in the two groups after 12, 24,48 , and $96 \mathrm{~h}$; the results showed that the proliferation of cells in the two groups is approximately the same after $12 \mathrm{~h}$ and $24 \mathrm{~h}$, but after $48 \mathrm{~h}$ and $96 \mathrm{~h}$, the proliferation capacity of $\mathrm{CD}^{-} 60^{-}\left(\mathrm{GPI}^{-}\right) \mathrm{T}$ cells is much higher than that of $\mathrm{CD} 160^{+}\left(\mathrm{GPI}^{+}\right)$ $\mathrm{T}$ cells, and the cytotoxicity mediated by $\mathrm{CD} 60^{-}\left(\mathrm{GPI}^{-}\right) \mathrm{CD}^{+}$ $\mathrm{T}$ cells was significantly higher than that mediated by $\mathrm{CD} 60^{+}\left(\mathrm{GPI}^{+}\right) \mathrm{CD}^{+} \mathrm{T}$ cells (37). Katagiri et al. found that HVEM significantly inhibited the proliferation of $\mathrm{GPI}^{+}$ memory $\mathrm{T}$ cells, but it did not affect the proliferation of $\mathrm{GPI}^{-}$ memory $\mathrm{T}$ cells; in their point of view, memory $\mathrm{T}$ cells act like HSCs in some ways (38). The most possible explanation is that HSCs expressing some GPI-APs are very similar to memory $\mathrm{T}$ cells in Katagiri's experiment, which express CD160; both of them may become invulnerable to some inhibitory proteins (e.g., HVEM) if they lack GPI-APs.

\section{The Apoptosis of GPI- Cells Differs From the Apoptosis of GPI+ Cells in Patients With PNH}

Kunyaboon et al. found that $\mathrm{CD} 59^{+}$granulocytes showed more apoptosis than $\mathrm{CD}^{-} 9^{-}$granulocytes in $\mathrm{PNH}$ patients after being in the liquid growth culture system for $0 \mathrm{~h}$ and $4 \mathrm{~h}$ (39). FasL binds to Fas, which results in cell apoptosis (40). Ismall et al. found that the apoptosis rate of $\mathrm{CD} 34^{+} \mathrm{CD} 59^{-}$cells was significantly lower than that of $\mathrm{CD} 34^{+} \mathrm{CD} 59^{+}$cells from the same $\mathrm{PNH}$ patient, and Fas expression was lower in $\mathrm{CD}^{-} 9^{-}$cells than that in $\mathrm{CD}_{5} 9^{+}$cells in $3 \mathrm{PNH}$ patients (41). The CD $34^{+} /$ $\mathrm{CD}_{59}{ }^{+}$cells in $\mathrm{PNH}$ patients seem to act similarly to the CD $34^{+}$ cells in AA in terms of higher apoptosis with higher expression of Fas (42); however, the $\mathrm{CD} 34^{+} / \mathrm{CD} 59^{-}$cells did not. Liu et al. separated $\mathrm{CD} 160^{+}\left(\mathrm{GPI}^{+}\right) \mathrm{CD}^{+} \mathrm{T}$ cells and $\mathrm{CD} 160^{-}\left(\mathrm{GPI}^{-}\right) \mathrm{CD} 8^{+}$ $\mathrm{T}$ cells into two different groups and then stimulated cells in the two groups by IL-2; they found that after $48 \mathrm{~h}$ and $96 \mathrm{~h}$, the 
apoptosis rate of $\mathrm{CD} 60^{+}\left(\mathrm{GPI}^{+}\right) \mathrm{T}$ cells is much higher than that of $\mathrm{CD}^{-160^{-}}\left(\mathrm{GPI}^{-}\right)$T cells (37). These suggest a further hypothesis that $\mathrm{GPI}^{-} \mathrm{HSCs}$ are resistant to apoptosis caused by cytokines, which may be related to the Fas/FasL pathway.

\section{The Relationship Between the Differences Mentioned Above and T Lymphocytes}

Kunyaboon et al. found that $\mathrm{CD}^{+} \mathrm{T}$ lymphocytes inhibited CFU-GM and BFU-E colony formation of PNH patients (39). This suggests that $\mathrm{T}$ lymphocytes may play a role in the pathogenesis of $\mathrm{PNH}$. Based on the immune escape hypothesis, Murakami et al. found that compared to mice without $\mathrm{CD} 4^{+} \mathrm{T}$ cells, ratios of fetal liver-derived cells in polymorphonuclear cells (PMNCs) and monocytes were smaller in $\mathrm{CD}^{+} \mathrm{T}$ cells cotransplanted mice; however, ratios of $\mathrm{GPI}^{-}$cells in PMNCs and monocytes in $\mathrm{CD}^{+} \mathrm{T}$ cells co-transplanted mice were significantly increased, suggesting that $\mathrm{GPI}^{+}$cells were selectively killed and GPI- cells survived (14). Ikeda et al. found that the number of Wilms' tumor gene (WT1) peptidespecific cytotoxic $\mathrm{CD}^{+} \mathrm{T}$ lymphocytes and the number of interferon (IFN)- $\boldsymbol{\gamma}$-producing mononuclear cells (MNC) stimulated by WT1 in peripheral blood of 5 patients with $\mathrm{PNH}$ were significantly increased compared with 8 normal controls. WT1 peptide-specific and human leukocyte antigen (HLA)restricted CTL clone (TAK-1) cells inhibited the formation of both $\mathrm{CD} 34^{+} \mathrm{CD} 59^{+}$cells and $\mathrm{CD} 34^{+} \mathrm{CD} 59^{-}$cell colonies. After co-culture with TAK-1 cells, the inhibition rate of $\mathrm{CD} 34^{+} \mathrm{CD} 59^{-}$ cell colony formation in $5 \mathrm{PNH}$ patients was significantly lower than that of $\mathrm{CD} 34^{+} \mathrm{CD} 59^{+}$cells, suggesting that WT1 peptidespecific and HLA-restricted cytotoxic $\mathrm{T}$ cells may play an important role in immune escape of $\mathrm{PNH}$, which may be related to interferon- $\gamma$ (43). These lines of evidence indicate that T lymphocytes may kill the $\mathrm{GPI}^{+}$cells selectively, while $\mathrm{GPI}^{-}$ cells can escape from immunologic attack.

\section{THE POSSIBLE ROLE OF T LYMPHOCYTES IN THE PATHOGENESIS OF PNH}

\section{T Lymphocytes May Play a Role Through GPI Molecule}

Rotoli et al. proposed the hypothesis that in the pathogenesis of $\mathrm{PNH}$, autoimmune T lymphocytes attack $\mathrm{GPI}^{+} \mathrm{HSC}$ cells through GPI molecules, while GPI' HSC cells can escape and survive (44). CD1d is a kind of MHC molecule that presents sugars/glycolipids that can induce T-cell immune responses; it is involved in the pathogenesis of a variety of diseases (45). Joyce et al. found that CD1d can present GPI anchor molecules (46). Thus, Karadimitris hypothesized that CD1d would present GPI molecule as antigen to $\mathrm{T}$ lymphocytes and then activate them. These $\mathrm{T}$ cells kill target cells that express GPI molecule; however, the PNH HSC, which lacks GPI molecules or has none at all, can escape from this attack (5). Gargiulo et al. analyzed the sequence of CDR-3 of TCR- $\beta$, and they found that identical or similar TCR- $\beta$ chains were enriched in $\mathrm{CD}^{2} 7^{+} \mathrm{CD}^{+} \mathrm{T}$ cells in $\mathrm{PNH}$ patients but not in normal controls, suggesting that auto-reactive $\mathrm{T}$ lymphocytes share a common target in most $\mathrm{PNH}$ patients (47). They also found that both exogenous and endogenous GPI molecules can activate CD1d restrictive $\mathrm{T}$ cells. This kind of $\mathrm{T}$ cells, known as the GPI specificity, CD1d-restrictive T cells, increased 10 times in $\mathrm{PNH}$ patients compared to normal control (48); this proof further supports the idea that $\mathrm{T}$ lymphocytes play the role of CTL by
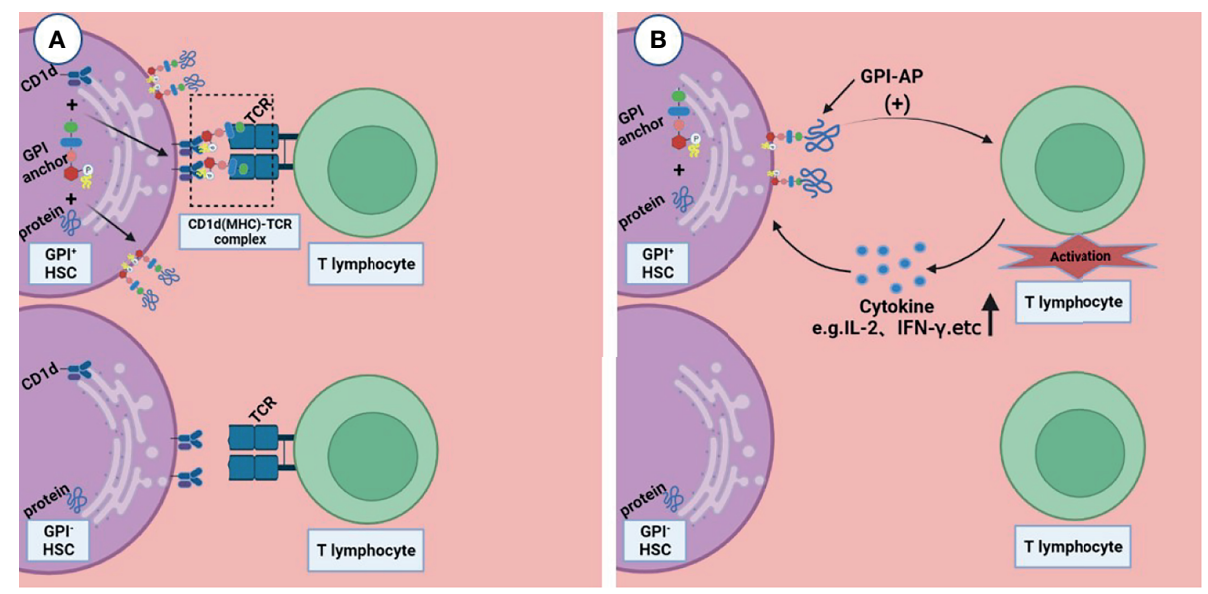

FIGURE 2 | Two possible ways that T lymphocytes are involved in the pathogenesis of immune escape. (A) CD1d presents GPI molecule as antigen to T lymphocytes and then activates them, these T lymphocytes kill the GPI ${ }^{+} \mathrm{HSC}$; however, the $\mathrm{GPI}^{-} \mathrm{HSC}$ can escape from this attack. (B) GPI-AP mediates the activation of T lymphocytes and promotes the release of its cytokines (e.g., IL-2), then T lymphocytes kill HSCs expressing GPI-APs; however, HSCs do not express GPI-APs escape from this effect. Figures were created in BioRender.com. 
targeting GPI molecule by the CD1d(MHC)-TCR complex, and the $\mathrm{GPI}^{-}$HSCs can escape from immune attack, although the specific mechanism is still unclear (Figure 2A).

\section{T Lymphocytes May Play a Role Through GPI-APs}

Deckert et al. found that there are at least two pathways in the activation of T cells through CD59, resulting in the production of IL-2 (49); this suggests that GPI-AP as a co-stimulator mediates the cytotoxicity of T lymphocytes (Figure 2B). NT4.2 is a unique $\mathrm{CD}^{+}{ }^{+} \mathrm{T}$ cell clone isolated by Nakao et al. from the bone marrow of AA patients, which strongly inhibited colony formation by HSPC (50). Takami et al. found that NT4.2 began to lyse LCL cells within $2 \mathrm{~h}$ and exhibited maximum cytotoxicity within $3 \mathrm{~h}$. Anti-DR, CD2, CD3, CD58, and CD59 monoclonal antibodies (mAbs) were used to block the cytotoxic effect, and the results showed that all of the mAbs block the cytotoxic effect to the same degree, indicating that CD59 on the LCL surface, as a kind of GPI-APs, is required by $\mathrm{T}$ lymphocytes to produce a cytotoxic effect on target cells (51). CD4 ${ }^{+}$CTL produces cytotoxicity mainly via the Fas/FasL pathway (52). Ismall et al. studied 10 patients with $\mathrm{PNH}$, and the expression of Fas in $\mathrm{CD} 59^{+}$cells were significantly higher than that in $\mathrm{CD}^{-} 9^{-}$cells in 3 patients (41). The Fas/FasL pathway is one of the apoptotic membrane receptor pathways (53). It is not difficult to speculate that $\mathrm{T}$ lymphocytes exerted cytotoxic effects through GPI-AP molecule via the Fas/FasL pathway, and $\mathrm{CD}_{5} 9^{+}$cells exhibited more apoptosis, while CD59 ${ }^{-}$cells could escape this cytotoxic effect.

\section{PERSPECTIVES}

According to the results of the present studies, $P I G-A$ gene mutation is widely considered as one of the pathogenesis of $\mathrm{PNH}$, but there are at least 20 genes that are involved in GPI

\section{REFERENCES}

1. Rachidi S, Musallam KM, Taher AT. A Closer Look at Paroxysmal Nocturnal Hemoglobinuria. Eur J Intern Med (2010) 21(4):260-7. doi: 10.1016/ j.ejim.2010.04.002

2. Brodsky RA. Paroxysmal Nocturnal Hemoglobinuria. Blood (2014) 124 (18):2804-11. doi: 10.1182/blood-2014-02-522128

3. Richards SJ, Painter D, Dickinson AJ, Griffin M, Munir T, Arnold L, et al. The Incidence and Prevalence of Patients With Paroxysmal Nocturnal Haemoglobinuria and Aplastic Anaemia PNH Syndrome: A Retrospective Analysis of the UK's Population-Based Haematological Malignancy Research Network 2004-2018. Eur J Haematol (2021) 107(2):211-8. doi: 10.1111/ejh. 13640

4. Illingworth AJ, Marinov I, Sutherland DR. Immunophenotyping of Paroxysmal Nocturnal Hemoglobinuria(PNH). Methods Mol Biol (2019) 2032:323-54. doi: 10.1007/978-1-4939-9650-6_18

5. Karadimitris A, Luzzatto L. The Cellular Pathogenesis of Paroxysmal Nocturnal Haemoglobinuria. Leukemia (2001) 15(8):1148-52. doi: 10.1038/ sj.leu. 2402180

6. Lukacik P, Roversi P, White J, Esser D, Smith GP, Billington J, et al. Complement Regulation at the Molecular Level: The Structure of Decay- biosynthesis in addition to $P I G-A$, and additional genetic changes occurring in $P I G$ - $A$-mutant HSCs could give these HSC clones a benign growth advantage (2). PIG-A gene mutation alone cannot explain the survival advantage of $\mathrm{PNH}$ clones, and it is not the only difference between the PNH clone and the non-PNH clone. Some researchers believe that it is the immunity of abnormal $\mathrm{T}$ lymphocytes that may be involved in the pathogenesis of $\mathrm{PNH}$. The occurrence of $\mathrm{PNH}$ is due to the escape of $\mathrm{GPI}^{-} \mathrm{HSC}$ from the $\mathrm{T}$ cell-mediated autoimmune attack on $\mathrm{GPI}^{+}$HSCs, which is known as immune escape hypothesis. IST therapy towards $\mathrm{T}$ lymphocyte is effective in some patients with $\mathrm{PNH}$. However, $\mathrm{PNH}$ patients are rare and IST or other treatments have only been applied in very few cases, and the idea of immune escape still lacks evidence. The specific role that $\mathrm{T}$ lymphocytes play is still unclear, which requires further study until it can be discovered. Fully understanding the role of autoimmunity in that $\mathrm{T}$ lymphocytes are involved in the pathogenesis of $\mathrm{PNH}$ may provide more new and accurate strategies in treatment, which may slow down the attack from T lymphocytes on HSCs without $P I G-A$ gene mutation and improve the quality of life of patients.

\section{AUTHOR CONTRIBUTIONS}

$\mathrm{ZS}$ and $\mathrm{XD}$ contributed to the conception and design of the study. CL wrote this manuscript. ZS, XD, and HW revised this manuscript. All authors contributed to manuscript revision, read, and approved the submitted version.

\section{FUNDING}

This study is supported by the grant (32100656 to XD) from the National Natural Science Foundation of China.
Accelerating Factor. Proc Natl Acad Sci USA (2004) 101(5):1279-84. doi: 10.1073/pnas.0307200101

7. Kinoshita T. Congenital Defects in the Expression of the Glycosylphosphatidylinositol-Anchored Complement Regulatory Proteins CD59 and Decay-Accelerating Factor. Semin Hematol (2018) 55(3):136-40. doi: 10.1053/j.seminhematol.2018.04.004

8. Luzzatto L, Karadimitris A. Paroxysmal Nocturnal Haemoglobinuria (PNH): Novel Therapies for an Ancient Disease. Br J Haematol (2020) 191(4):579-86. doi: $10.1111 /$ bjh.17147

9. Gavriilaki E, Peffault de Latour R, Risitano AM. Advancing Therapeutic Complement Inhibition in Hematologic Diseases: PNH and Beyond. Blood (2021), blood.2021012860. doi: 10.1182/blood.2021012860

10. Gavriilaki E, Brodsky RA. Complementopathies and Precision Medicine. J Clin Invest (2020) 130(5):2152-63. doi: 10.1172/JCI136094

11. Markiewicz M, Drozd-Sokolowska J, Biecek P, Dzierzak-Mietla M, Boguradzki P, Staniak M, et al. Allogeneic Hematopoietic Stem Cell Transplantation for Paroxysmal Nocturnal Hemoglobinuria: Multicenter Analysis by the Polish Adult Leukemia Group. Biol Blood Marrow Transplant (2020) 26(10):1833-9. doi: 10.1016/j.bbmt.2020.05.024

12. Nishimura J, Kanakura Y. Paroxysmal Nocturnal Hemoglobinuria (PNH). Nihon Rinsho (2008) 66(3):490-6. 
13. Rosti V, Tremml G, Soares V, Pandolfi PP, Luzzatto L, Bessler M. Murine Embryonic Stem Cells Without Pig-a Gene Activity are Competent for Hematopoiesis With the PNH Phenotype But Not for Clonal Expansion. J Clin Invest (1997) 100(5):1028-36. doi: 10.1172/JCI119613

14. Murakami Y, Kosaka H, Maeda Y, Nishimura J, Inoue N, Ohishi K, et al. Inefficient Response of $\mathrm{T}$ Lymphocytes to Glycosylphosphatidylinositol Anchor-Negative Cells: Implications for Paroxysmal Nocturnal Hemoglobinuria. Blood (2002) 100(12):4116-22. doi: 10.1182/blood-200206-1669

15. Luzzatto L. Recent Advances in the Pathogenesis and Treatment of Paroxysmal Nocturnal Hemoglobinuria. F1000Res (2016) 5:F1000 Faculty Rev-209. doi: 10.12688/f1000research.7288.1

16. Szeto C, Lobos CA, Nguyen AT, Gras S. TCR Recognition of Peptide-MHC-I: Rule Makers and Breakers. Int J Mol Sci (2020) 22(1):68. doi: 10.3390/ ijms22010068

17. Risitano AM, Kook H, Zeng W, Chen G, Young NS, Maciejewski JP. Oligoclonal and Polyclonal CD4 and CD8 Lymphocytes in Aplastic Anemia and Paroxysmal Nocturnal Hemoglobinuria Measured by V Beta CDR3 Spectratyping and Flow Cytometry. Blood (2002) 100(1):178-83. doi: 10.1182/blood-2002-01-0236

18. Risitano AM, Maciejewski JP, Muranski P, Wlodarski M, O'Keefe C, Sloand EM, et al. Large Granular Lymphocyte (LGL)-Like Clonal Expansions in Paroxysmal Nocturnal Hemoglobinuria (PNH) Patients. Leukemia (2005) 19 (2):217-22. doi: 10.1038/sj.leu.2403617

19. Young NS, Maciejewski JP, Sloand EM, Chen G, Zeng W, Risitano A, et al. The Relationship of Aplastic Anemia and PNH. Int J Hematol (2002) 76:16872. doi: $10.1007 / \mathrm{BF} 03165111$

20. Schrezenmeier H, Muus P, Socie G, Szer J, Urbano-Ispizua A, Maciejewski JP, et al. Baseline Characteristics and Disease Burden in Patients in the International Paroxysmal Nocturnal Hemoglobinuria Registry. Haematologica (2014) 99(5):922-9. doi: 10.3324/haematol.2013.093161

21. Frickhofen N, Rosenfeld SJ. Immosuppressive Treatment of Aplastic Anemia With Antithymocyte Globin and Cyclosporine. Semin Hematol (2000) 37:5668. doi: 10.1016/S0037-1963(00)90030-1

22. Issaragrisil S, Piankijagum A, Chinprasertsuk S, Kruatrachue M. Growth of Mixed Erythroid-Granulocytic Colonies in Culture Derived From Bone Marrow of Patients With Paroxysmal Nocturnal Hemoglobinuria Without Addition of Exogenous Stimulator. Exp Hematol (1986) 14(9):861-6.

23. Luzzatto L, Risitano AM. Advances in Understanding the Pathogenesis of Acquired Aplastic Anaemia. Br J Haematol (2018) 182(6):758-76. doi: 10.1111/bjh.15443

24. Kordasti S, Marsh J, Al-Khan S, Jiang J, Smith A, Mohamedali A, et al. Functional Characterization of CD4+ T Cells in Aplastic Anemia. Blood (2012) 119(9):2033-43. doi: 10.1182/blood-2011-08-368308

25. Zeng Y, Katsanis E. The Complex Pathophysiology of Acquired Aplastic Anaemia. Clin Exp Immunol (2015) 180(3):361-70. doi: 10.1111/cei.12605

26. Kulagin A, Lisukov I, Ivanova M, Golubovskaya I, Kruchkova I, Bondarenko S, et al. Prognostic Value of Paroxysmal Nocturnal Haemoglobinuria Clone Presence in Aplastic Anaemia Patients Treated With Combined Immunosuppression: Results of Two-Centre Prospective Study. $\mathrm{Br} \mathrm{J}$ Haematol (2014) 164(4):546-54. doi: 10.1111/bjh.12661

27. Ren X, Li X, Huo J, You Y, Huang J, Shao Y, et al. Small PNH Clones Detected by Fluorescent Aerolysin Predict a Faster Response to Immunosuppressive Therapy in Patients With Severe Aplastic Anaemia. Hematology (2020) 25 (1):348-55. doi: 10.1080/16078454.2020.1821495

28. Paquette RL, Yoshimura R, Veiseh C, Kunkel L, Gajewski J, Rosen PJ. Clinical Characteristics Predict Response to Antithymocyte Globulin in Paroxysmal Nocturnal Haemoglobinuria. Br J Haematol (1997) 96(1):92-7. doi: 10.1046/ j.1365-2141.1997.d01-1984.x

29. Nakasone H, Iijima K, Asano H, Nakamura F, Kida M, Izutsu K, et al. Immunosuppressive Therapy With Antithymocyte Globulin and Cyclosporine for Paroxysmal Nocturnal Hemoglobinuria. Rinsho Ketsueki (2008) 49(7):498-504. doi: 10.11406/rinketsu.49.498

30. Schubert J, Vogt HG, Zielinska-Skowronek M, Freund M, Kaltwasser JP, Hoelzer D, et al. Development of the Glycosylphosphatitylinositol-Anchoring Defect Characteristic for Paroxysmal Nocturnal Hemoglobinuria in Patients With Aplastic Anemia. Blood (1994) 83(8):2323-8. doi: 10.1182/ blood.V83.8.2323.2323
31. Li YM, Li XX, Ge ML, Shi J, Shao YQ, Qian LS, et al. The Clinical Significance of Evolution of Paroxysmal Nocturnal Haemoglobinuria Clones in Aplastic Anemia Patients. Zhonghua Xue Ye Xue Za Zhi (2012) 33(2):117-22. doi: 10.3760/cma.j.issn.0253-2727.2012.02.013

32. Zhang J, Li X, Shi J, Ge M, Shao Y, Huang J, et al. Clinical Characteristics and Evolution of Paroxysmal Nocturnal Hemoglobinuria Clones in Patients With Acquired Aplastic Anemia. Zhonghua Xue Ye Xue Za Zhi (2016) 37(2):124-9. doi: 10.3760/cma.j.issn.0253-2727.2016.02.008

33. Han B, Wu Y, Lu Z, Zhang Z. Proliferative Capacity of the Isolated Single CD $(34)(+)$ Glycosylphosphatidylinesitol-Anchored (GPI) Protein Negative and Positive Hematopoietic Cells in Paroxysmal Nocturnal Hemoglobinuria. Zhonghua Xue Ye Xue Za Zhi (2002) 23(5):233-5. doi: 10.3969/j.issn.10092137.2002.01.011

34. Le Bouteiller P, Tabiasco J, Polgar B, Kozma N, Giustiniani J, Siewiera J, et al. CD160: A Unique Activating NK Cell Receptor. Immunol Lett (2011) 138 (2):93-6. doi: 10.1016/j.imlet.2011.02.003

35. Kojima R, Kajikawa M, Shiroishi M, Kuroki K, Maenaka K. Molecular Basis for Herpesvirus Entry Mediator Recognition by the Human Immune Inhibitory Receptor CD160 and its Relationship to the Cosignaling Molecules BTLA and LIGHT. J Mol Biol (2011) 413(4):762-72. doi: 10.1016/j.jmb.2011.09.018

36. Cai G, Anumanthan A, Brown JA, Greenfield EA, Zhu B, Freeman GJ. CD160 Inhibits Activation of Human CD4+ T Cells Through Interaction With Herpesvirus Entry Mediator. Nat Immunol (2008) 9:176-85. doi: 10.1038/ ni1554

37. Liu S, Zhang W, Liu K, Wang Y. CD160 Expression on CD8(+) T Cells is Associated With Active Effector Responses But Limited Activation Potential in Pancreatic Cancer. Cancer Immunol Immunother (2020) 69(5):789-97. doi: 10.1007/s00262-020-02500-3

38. Katagiri T, Qi Z, Ohtake S, Nakao S. GPI-Anchored Protein-Deficient T Cells in Patients With Aplastic Anemia and Low-Risk Myelodysplastic Syndrome: Implications for the Immunopathophysiology of Bone Marrow Failure. Eur J Haematol (2011) 86(3):226-36. doi: 10.1111/j.1600-0609.2010.01563.x

39. Kunyaboon R, Wanachiwanawin W, U-Pratya Y, Thedsawad A, Taka O. Mechanism of Paroxysmal Nocturnal Hemoglobinuria Clonal Dominance: Possible Roles of Different Apoptosis and CD8+ Lymphocytes in the Selection of Paroxysmal Nocturnal Hemoglobinuria Clones. Hematol Oncol Stem Cell Ther (2012) 5(3):138-45. doi: 10.5144/1658-3876.2012.138

40. Nagata S. Fas-Induced Apoptosis, and Diseases Caused by its Abnormality. Genes Cells (1996) 1(10):873-9. doi: 10.1046/j.1365-2443

41. Ismail MM, Tooze JA, Flynn JA, Gordon-Smith EC, Gibson FM, Rutherford TR, et al. Differential Apoptosis and Fas Expression on GPI-Negative and GPI-Positive Stem Cells: A Mechanism for the Evolution of Paroxysmal Nocturnal Haemoglobinuria. Br J Haematol (2003) 123(3):545-51. doi: 10.1046/j.1365-2141.2003.04643.x

42. Maciejewski JP, Selleri C, Sato T, Anderson S, Young NS. Increased Expression of Fas Antigen on Bone Marrow CD34+ Cells of Patients With Aplastic Anaemia. Br J Haematol (1995) 91(1):245-52. doi: 10.1111/j.13652141.1995.tb05277.x

43. Ikeda K, Shichishima T, Yasukawa M, Nakamura-Shichishima A, Noji H, Akutsu K, et al. The Role of Wilms' Tumor Gene Peptide-Specific Cytotoxic T Lymphocytes in Immunologic Selection of a Paroxysmal Nocturnal Hemoglobinuria Clone. Exp Hematol (2007) 35(4):618-26. doi: 10.1016/ j.exphem.2007.01.045

44. Rotoli B, Luzzatto L. Paroxysmal Nocturnal Hemoglobinuria. Semin Hematol (1989) 26(3):201-7.

45. Kumar H, Belperron A, Barthold SW, Bockenstedt LK. Cutting Edge: CD1d Deficiency Impairs Murine Host Defense Against the Spirochete, Borrelia Burgdorferi. J Immunol (2000) 165(9):4797-801. doi: 10.4049/jimmunol. 165.9.4797

46. Joyce S, Woods As, Yewdell JW. Natural Ligand of Mouse CD1d: Cellular in Glycosylphosphatidy Linositol. Science (1998) 279(5356):1541-9. doi: $10.1126 /$ science. 279.5356 .1541

47. Gargiulo L, Lastraioli S, Cerruti G, Serra M, Loiacono F, Zupo S, et al. Highly Homologous T-Cell Receptor Beta Sequences Support a Common Target for Autoreactive T Cells in Most Patients With Paroxysmal Nocturnal Hemoglobinuria. Blood (2007) 109(11):5036-42. doi: 10.1182/blood-200610-052381 
48. Gargiulo L, Papaioannou M, Sica M, Talini G, Chaidos A, Richichi B, et al. Glycosylphosphatidylinositol-Specific, CD1d-Restricted T Cells in Paroxysmal Nocturnal Hemoglobinuria. Blood (2013) 121(14):2753-61. doi: 10.1182/blood-2012-11-469353

49. Deckert M, Ticchioni M, Mari B, Mary D, Bernard A. The Glycosylphosphatidylinositol-Anchored CD59 Protein Stimulates Both T Cell Receptor Zeta/ZAP-70-Dependent and -Independent Signaling Pathways in T Cells. Eur J Immunol (1995) 25(7):1815-22. doi: 10.1002/eji. 1830250704

50. Nakao S, Takami A, Takamatsu H, Zeng W, Sugimori N, Yamazaki H, et al. Isolation of a T-Cell Clone Showing HLA-DRB1*0405-Restricted Cytotoxicity for Hematopoietic Cells in a Patient With Aplastic Anemia. Blood (1997) 89 (10):3691-9. doi: 10.1182/blood.V89.10.3691

51. Takami A, Zeng W, Wang H, Matsuda T, Nakao S. Cytotoxicity Against Lymphoblastoid Cells Mediated by a T-Cell Clone From an Aplastic Anaemia Patient: Role of CD59 on Target Cells. Br J Haematol (1999) 107(4):791-6. doi: 10.1046/j.1365-2141.1999.01790.x

52. Stalder T, Hahn S, Erb P. Fas Antigen is the Major Target Molecule for CD4+ T Cell-Mediated Cytotoxicity. J Immunol (1994) 152(3):1127-33.
53. Nagata S. Fas Ligand-Induced Apoptosis. Annu Rev Genet (1999) 33:29-55. doi: 10.1146/annurev.genet.33.1.29

Conflict of Interest: The authors declare that the research was conducted in the absence of any commercial or financial relationships that could be construed as a potential conflict of interest.

Publisher's Note: All claims expressed in this article are solely those of the authors and do not necessarily represent those of their affiliated organizations, or those of the publisher, the editors and the reviewers. Any product that may be evaluated in this article, or claim that may be made by its manufacturer, is not guaranteed or endorsed by the publisher.

Copyright (c) 2021 Li, Dong, Wang and Shao. This is an open-access article distributed under the terms of the Creative Commons Attribution License (CC BY). The use, distribution or reproduction in other forums is permitted, provided the original author(s) and the copyright owner(s) are credited and that the original publication in this journal is cited, in accordance with accepted academic practice. No use, distribution or reproduction is permitted which does not comply with these terms. 